\title{
Las medidas para el desarrollo del gobierno local en España y sus implicaciones con la Carta Europea de la Autonomía Local *
}

José Manuel Rodríguez Álvarez **

I. La importancia de la Carta Europea de la Autonomía Local en el ámbito continental y su actualidad en un contexto de globalización

La Carta Europea de la Autonomía Local constituye un singular Convenio internacional, con una transcendencia jurídica y política creciente, fruto de su decidida vocación de convertirse en la verdadera "Constitución" de la autonomía local en el continente europeo. Y esta importancia se ha incrementado en los últimos años porque, como ha destacado el Secretario General del Consejo de Europa, Daniel TaRSCHYS, se ha convertido en el texto de referencia que ha permitido a las nuevas democracias de Europa central y oriental adoptar regímenes jurídicos conformes con las democracias europeas tradicionales ${ }^{1}$.

Resulta del mayor interés, para valorar adecuadamente la trascendental importancia de este Convenio, recordar sucintamente las circunstancias que justificaron su gestación en el seno del
Consejo de Europa. Esta organización internacional, que surgió precisamente en plena postguerra europea, en el año 1949, tiene como finalidad, de acuerdo con el artículo $1^{\circ}$ de su Estatuto, "realizar una unión más estrecha entre sus miembros para salvaguardar y promover los ideales y los principios que constituyen el patrimonio común y favorecer su progreso económico y sociab. Se iniciaba así la institucionalización de una idea integradora como necesidad ineludible después de la experiencia de dos guerras mundiales que habían arrasado buena parte del continente.

Muy pronto comprendió el Consejo de Europa la importancia que para el logro de la unidad europea tenía la participación y el apoyo activo de su población y de sus representantes más inmediatos, los electos locales, quienes podían ser poderosos aliados del Consejo en sus esfuerzos para salvaguardar los ideales y principios que constituyen la común herencia de Europa, íntimamente unida a la existencia de organizaciones locales. En efecto, tras la experiencia de la expansión de las ideologías totalitarias en el período de entreguerras y su desembocamiento en la gran conflagración de 1939-1945, para Europa resultaba fundamental, por un lado, mantener y fortalecer un espacio democrático local como elemento esencial de democracia europea y, por otro, usar la dimensión participativa de la democracia local para conectar con los individuos y transmitirles el ideal de la unidad europea, produciéndose un vínculo entre las ideas de democracia y municipio, porque si no se produce el arraigo del ideal democrático allí donde resulta más fácil, difícil será que se traslade a ámbitos institucionales como el marco europeo. 
En el fondo, el Consejo de Europa percibe la enorme funcionalidad política de los gobiernos locales como escuela de participación ciudadana y de democracia, mediante un silogismo implicito pero enormemente eficaz para la realización de sus fines: si Europa es igual a democracia y el municipio es igual a democracia, Europa es igual a municipio.

Sobre este transfondo ideológico (y también pragmático) se desarrolló el largo y laborioso proceso de gestación de la Carta Europea de la Autonomía Local, cuyo germen originario hay que encontrarlo en la creación el 27 de septiembre de 1952 de una Comisión de Asuntos Municipales y Regionales, y que fructifica definitivamente con la apertura del Convenio a la firma de los Estados miembros el día 15 de octubre de $1985^{2}$, en Estrasburgo, y además en forma de verdadero Convenio internacional, y no de mera recomendación, como pretendían algunos de los Estados miembros, que mantenían una posición afortunadamente minoritaria ${ }^{3}$. Su redacción final es el producto, pues, de un laborioso proceso de decantación, en el que sus elaboradores partieron de una amplia tradición histórico-política y doctrinal, en cuya configuración habían confluido diversas teorías -las doctrinas francesas del pouvoir municipal y de la descentralización, la teoría germánica de la asociación y el Self Government anglosajón-, que han acabado por sintetizarse en los principios que la Carta recoge.

Para hacerse una idea de la difusión de la Carta, basta señalar que de los 40 Estados miembros del Consejo de Europa, a comienzos del año 1998 ya la habían firmado 34, y ratificado 27 de ellos, incorporándola a su ordenamiento jurídico como pieza fundamental de la autonomía local, con los compromisos que para la organización territorial de cada Estado y para la distribución de poder entre las diversas instancias territoriales comporta la aceptación de un Convenio internacional de este alcance y naturaleza. Y se va camino de una pronta ratificación por parte de los Estados que aún no lo han hecho.

Pues bien, la importancia de un Convenio como la Carta Europea de la Autonomía Local para la garantía de ésta se acrecienta en el contexto de un mundo globalizado. En efecto, los procesos de transformación estructural que está experimentando la sociedad contemporánea se manifiestan, de forma muy destacada, en la consolidación de una aeconomía globaln y de una asociedad de la información. Y en un contexto de digitalización de la comunicación, de política mediática y de crisis de los Estados nacionales, las ciudades están viviendo una profunda transformación estructural de dimensiones realmente históricas, lo que plantea nuevas exigencias en el terreno de la gestión urbana. En este contexto, las ciudades dependen cada vez más de su articulación en la economía local, siendo la nueva frontera de la gestión colocar a cada ciudad en condiciones de afrontar la competición global de que depende el bienestar de su población. Algo que, en opinión de BorJa y CASTELLS ${ }^{4}$, depen- derá de tres factores esenciales: la conectividad, la capacidad de innovación y la flexibilidad institucional de que hagan prueba sus gestores.

Pues bien, en el marco de este mundo globalizado, la revalorización de lo local no sólo es posible, sino que constituye el contrapeso político necesario a la multinacionalización económica del nuevo sistema. Es necesaria una relación dinámica y creativa entre lo global y lo local, que permita una renovación del hecho urbano y la conservación de su identidad como una necesidad esencial en este mundo globalizado, como contrapeso a los procesos de pérdida de identidad y del alejamiento de las instancias de decisión económicas y políticas de los ciudadanos. Aunque para ello las ciudades deberán actuar en forma de redes, cooperando, coordinándose, apoyándose y complementándose, superando así las desventajas y limitaciones de la fragmentación propia de lo local.

Ahora bien, las políticas urbanas que deben desarrollarse en este marco de globalización son extraordinariamente complejas y difíciles, moviéndose entre las exigencias teóricas de la competitividad y las dinámicas prácticas generadas por la competencia entre grupos y territorios, lo que conduce a la necesidad de un mayor ámbito competencial y funcional en manos de los gobiernos locales para el adecuado desarrollo de sus responsabilidades, así como la reforma política y administrativa de estos gobiernos para mejorar y hacer efectiva la gobernabilidad, imprescindible más aún en una situación en la que los gobiernos locales deben actuar como verdaderos promotores de la ciudad y como coordinadores de los diversos actores sociales y económicos locales, ejercitando un liderazgo imprescindible.

Resulta evidente que en este contexto la funcionalidad de un instrumento como la Carta Europea de la Autonomía Local y de sus grandes principios permanece y se acrecienta, dando muestras del acierto de sus planteamientos y de la madurez y visión de futuro con que fue concebida en el seno del Consejo de Europa. La Carta, como veremos, ofrece instrumentos y criterios para fortalecer netamente el papel de lo local en este mundo globalizado, ya que el dinamismo, la flexibilidad y la fuerza expansiva de sus criterios no responden a un mero ejercicio de romanticismo municipalista, sino a reflexiones profundas y a la decantación depurada de experiencias históricas, políticas e institucionales.

Por ello no puede extrañar en absoluto que la Carta Europea de la Autonomía Local haya consolidado e incrementado su prestigio jurídico y político, ni que haya tenido un decisivo papel en la inspiración de otros documentos de idéntica finalidad, como es el caso de la Carta de la Autonomía Local Iberoamericana, hecha en Caracas el 22 de noviembre de 1992 por la Organización Iberoamericana de Cooperación Intermunicipal (OICI), y lo continúe teniendo en el proceso de elaboración de la denominada Carta Mundial de la Autonomía Local, que se está gestando en el seno de la IULA ${ }^{5}$. 


\section{Contenido de la Carta. Especial referencia a los principios esenciales de democracia y subsidiariedad}

Conviene ya entrar a exponer sucintamente los principios fundamentales de este importante Convenio, que es un documento breve integrado por un Preámbulo y 17 artículos, estructurados en tres Partes.

El Preámbulo presenta especial interés, puesto que establece una nítida conexión entre la autonomía local y la noción de legitimidad democrática. En él se declara expresamente que "las Entidades locales son uno de los principales fundamentos de un régimen democrática, cuyos principios son comunes a todos los Estados miembros de Europa, siendo una de sus manifestaciones precisamente el derecho de los ciudadanos a participar en la gestión de los asuntos públicos, derecho que en el nivel local "puede ser ejercido más directamente mediante Entidades locales investidas de competencias efectivas que permiten "una Administración a la vez eficaz y próxima al ciudadano, basada en una amplia descentralización del poder. Esa descentralización se basa en que los redactores de la Carta se declaran "convencidos de que la existencia de Entidades locales investidas de competencias efectivas permite una administración a la vez eficaz y próxima al ciudadano.

Aquí nos encontramos otra de las ideas nucleares de la Carta: los principios-esenciales de democracia y subsidiariedad ( 0 , si se prefiere, de "proximidad.), que además se retroalimentan recíprocamente, en un decisivo feed-back para entender la funcionalidad de la autonomía local: la democracia local, para ser efectiva y no meramente "nominal" o semántica", requiere proyectarse sobre un ámbito importante de políticas, de responsabilidades públicas, que deben acercarse al nivel local $-y$, por lo tanto, a los ciudadanos-, aplicando el principio de subsidiariedad o proximidad. Y este principio desarrolla todas sus potencialidades de eficacia, eficiencia, ahorro de recursos y calidad del servicio ${ }^{6}$ en un contexto democrático, donde los ciudadanos pueden participar y/o incidir efectivamente sobre el gobierno local.

Los redactores de la Carta no sólo no ocultan, sino que hacen explícito el profundo impulso político europeísta que inspira su obra. La Carta debe su redacción a que son "conscientes de que la defensa y el fortalecimiento de la autonomia local en los diferentes paises de Europa representan una contribución esencial en la construcción de una Europa basada en los principios de democracia y descentralización del poder. Y evidentemente estos dos últimos principios, combinados, conducen a un resultado: suponen la existencia de Entidades locales dotadas de órganos de decisión democráticamente constituidos que se benefician de una amplia autonomia en cuanto a las competencias, a las modalidades de ejercicio de estas últimas y a los medios necesarios para el cumplimiento de su misión.

El esquema del Preámbulo, por lo tanto, no puede resultar más coherente con el espíritu fundacional del Consejo de Europa y con la tradición de la democracia local europea.

La parte dispositiva esencial de la Carta se contiene en su Parte Primera, que comprende 11 artículos que integran un total de 31 apartados?

Aquí no podemos - ni constituye nuestro objetivo- entrar en detalle en el contenido de esta Parte sustantiva de la Carta, que aborda el fundamento constitucional de la autonomía local (art. 2); su concepto y alcance (arts. 3 y 4); la protección de los limites territoriales de las Entidades locales (art. 5); la adecuación de sus estructuras y medios administrativos a sus cometidos (art. 6); las condiciones del ejercicio de las responsabilidades a nivel local (art. 7); el control administrativo de los actos de las Entidades locales (art. 8); sus recursos financieros (art. 9); el derecho de asociación de las Entidades locales (art. 10); y la protección legal de la autonomía local (art. 11). Aunque breve, en su conjunto la Carta constituye un magnífico ejercicio de síntesis y todos los aspectos esenciales de la autonomía local resultan abordados en ella.

Aquí nos interesa resaltar solamente algunos aspectos esenciales a los fines de nuestra exposición, concretamente el concepto de autonomía local; el principio democrático que rige sus gestión; la noción de subsidiariedad o "proximidad"; la autonomía y suficiencia financiera; el asociacionismo de las Entidades locales, y la protección legal de su autonomía.

Por lo que se refiere al concepto de la autonomía local, el artículo 3 la define en su apartado 1 como el derecho y la capacidad efectiva de las Entidades locales de ordenar y gestionar una parte importante de los asuntos públicos, en el marco de la Ley, bajo su responsabilidad y en beneficio de sus babitantes. De esta definición creo que debe destacarse la amplitud con la que está concebida dicha autonomía, puesto que:

a) Se concibe como derecho, pero debe concurrir la nota de la "capacidad efectiva", por lo que la Carta ha huido del mero reconocimiento formal o nominal.

b) Incluye no sólo la capacidad de "gestionar", sino también la de "ordenar" —e decir, "reguları, lo que tendrá ex- 
traordinarias consecuencias prácticas para la defensa de la autonomía local.

c) Por lo que se refiere al aspecto objetivo o sustantivo de la autonomia local, ésta debe incidir sobre una parte importante de los asuntos públicos.

d) Finalmente, en lo que se refiere al aspecto funcional de esta autonomía, la misma se ejerce bajo la propia responsabilidad de las Entidades locales, y en beneficio de sus habitantes.

Asimismo, el apartado 2 del artículo 3 contiene la consagración del principio democrático de la autonomía local, al señalar que "este derecho se ejerce por Asambleas o Consejos integrados por miembros elegidos por sufragio libre, secreto, igual, directo y universal y que pueden disponer de órganos ejecutivos responsables ante ellos mismos. Esta disposición no causará perjuicio al recurso a las asambleas de vecinos, al referéndum o a cualquier otra forma de participación directa de los ciudadanos, alli donde esté permitido por la Ley. El principio democrático queda garantizado, tanto en sus expresiones representativas como en sus manifestaciones de democracia directa, pero se permite expresamente la posibilidad de creación de órganos ejecutivos responsables ante los representativos del conjunto de los ciudadanos.

Por lo que se refiere al contenido del artículo 4, dedicado al alcance de la autonomía local, ha de destacarse, sin duda alguna, la consagración del principio de subsidiariedad o "proximidad", contenido en su apartado 3, que, sin embargo y paradójicamente, no forma parte del "núcleo obligatorio" previsto en su artículo 12, y en el que se declara que "el ejercicio de las competencias puiblicas debe, de modo general, incumbir preferentemente a las autoridades más cercanas a los ciudadanos. La atribución de una competencia a otra autoridad debe tener en cuenta la amplitud o la naturaleza de la tarea o las necesidades de eficacia o economiar. Se trata, sin duda, de una de las más perfectas y sintéticas definiciones de la noción de subsidiariedad, comprensiva de los elementos esenciales que han de ser considerados para la operatividad de tal principio.

El artículo 7 de la Carta está dedicado a los recursos financieros de las Entidades locales y en él, entre otros extremos, se recogen los principios de suficiencia y de autonomía financiera. Por lo que se refiere al primero, se declara que "Las entidades locales tienen derecho, en el marco de la politica económica nacional, a tener recursos propios suficientess (ap. 1) unos recursos que *deben ser proporcionales a las competencias previstas por la Constitución o por la Leys (ap. 2). Y en lo que respecta al principio de autonomía, se manifiesta tanto en la vertiente de los in- gresos - se prevé que "una parte importante de los recursos financieros debe provenir de ingresos patrimoniales y de tributos locales respecto de los que tengan la potestad de fijar la cuota 0 el tipo dentro de los limites de la Ley (ap. 3)-, como en la vertiente de los gastos - se dispone que de sus recursos apueden disponer libremente en el ejercicio de sus competencias" (ap. 1) y que "en la medida de lo posible, las subvenciones concedidas a las Entidades locales no deben ser destinadas a la financiación de proyectos especificos. La concesión de subvenciones no deberá causar perjuicio a la libertad fundamental de la politica de las Entidades locales, en su propio ámbito de competencia (ap. 7). Tiene especial importancia la consagración del carácter predominantemente no finalista de las subvenciones que perciban de otras Administraciones, y el reconocimiento expreso de un ámbito de autonomía propia para las políticas locales en el ejercicio de su competencia, lo que comporta la limitación de los abusos bajo la forma del denominado "control por el presupuesto", de amplia práctica tradicional en el mundo anglosajón- esencialmente, aunque no exclusivamente.

El articulo 10 regula el derecho de asociación de las Entidades locales, estableciendo el derecho de cooperación (aps. 1 y 3) y de asociación (aps. 1 y 2), tanto en el ámbito interno como en el internacional. Especial importancia tiene la previsión de que, además de poder crear asociaciones que tiene por finalidad la "realización de tareas de interés común, las Entidades locales tienen derecho a "integrarse en una asociación para la promoción de sus intereses comunes y el de integrarse en una asociación internacional de Entidades locales. Existe aquí una formalización expresa del lobbyng de las Entidades locales, que en este caso está además plenamente justificado en términos sistémicos debido a la fragmentación propia, intrínseca e inevitable (en mayor o menor medida) del mundo local, que haría ineficaz cualquier intento de actuación sobre otros elementos esenciales del sistema político-institucional si no actúan en forma de red o de redes estructuradas.

Finalmente, el artículo 11 se dirige a la protección legal de la autonomia local, y dispone que "las Entidades locales deben disponer de una vía de recurso jurisdiccional a fin de asegurar el libre ejercicio de sus competencias y el respeto a los principios de autonomia local consagrados en la Constitución o en la legislación. Se trata, sin duda, de una previsión esencial, pues de poco serviría el reconocimiento formal de la autonomía local en el ordenamiento jurídico, incluso en el nivel constitucional, si las Entidades locales no pueden esgrimirla en vía jurisdiccional para protegerla y defender su ámbito competencial frente a los otros niveles de poder territorial. 


\section{La necesidad del} fortalecimiento del poder local en España: del denominado "pacto local" a las "medidas para el desarrollo del gobierno local"

España es uno de los países del mundo occidental que ha realizado un mayor esfuerzo descentralizador durante los últimos veinte años, si no el que más. A partir de la aprobación de la Constitución de 1978, España ha pasado de ser un Estado profundamente centralizado a otro modelo de amplia descentralización políica, mediante la construcción del denominado "Estado autonómico", que se sitúa a medio camino entre los modelos regional y federal, posiblemente más cercano a este último.

Al mismo tiempo, a partir de las Elecciones locales de 1979, comienza la andadura de nuestros actuales gobiernos locales democráticos que han demostrado una gran eficacia y eficiencia en la consecución de sus objetivos, centrados esencialmente en el establecimiento de infraestructuras, equipamientos y servicios de carácter esencial para la vida colectiva, así como en la planificación y gestión urbanística, superando los grandes déficit acumulados en estas materias. Las políticas públicas locales en España incluso se han ido orientando en los años noventa hacia el desarrollo local, una vez superados los grandes déficit infraestructurales del pasado ${ }^{8}$. En todo caso, ese camino de potenciación de su autonomía encontrará un marco para su mejor desarrollo en un conjunto de medidas legislativas, entre las que deben destacarse la Ley $7 / 1985$, de 2 de abril, Reguladora de las Bases del Régimen Local, y la Ley Orgánica 5/1985, de 19 de junio, del Régimen Electoral General.

Sin embargo, el grado de eficacia y eficiencia de la Administración local española, en términos generales, así como la consolidación de su autonomía, no constituyen elementos suficientes para colocar el grado de responsabilidades de la Administración local, en el marco del conjunto de los distintos niveles territoriales de poder, en un lugar parangonable al que ocupa en otros Estados occidentales compuestos, descentralizados políticamente, considerándose de forma casi unánime que le corresponde un papel más relevante que el asumido hasta ahora, reflejado esencialmente en una participación relativamente reducida en el gasto público total. Lo que puede considerarse fruto, en buena medida, de la prioridad concedida al establecimiento y consolidación de las Comunidades Autónomas en la primera y compleja fase post-constitucional de desarrollo del proceso descentralizador español.

La distribución del gasto público total y su evolución resulta muy gráfica a la hora de valorar la importancia relativa de cada uno de los tres niveles: el estatal, el autonómico y el local. Así, de una distribución inicial, en el momento de la aprobación de nuestra Constitución, de un $91 \%$ para el Estado y un $9 \%$ para las Entidades locales, se ha pasado en la actualidad a otra en la que, según estimaciones para 1998, las Comunidades Autónomas están en torno al 26,91\%, las Entidades locales cerca del 13,61\%, y el Estado en un $59,48 \%$. Además, la tendencia descentralizadora del gasto público tiende a aumentar y en los próximos años, fundamentalmente como consecuencia de los traspasos de los servicios educativos a todas las Comunidades Autónomas que aún no los han recibido, es previsible que la participación de éstas en el gasto público total se sitúe en torno a un 36 o un 37\%, aproximadamente, y que la del Estado se reduzca a un $50 \%$.

Estas cifras nos demuestran que el panorama político espanol actual es, como se ha señalado, uno de los más descentralizados en materia de políticas públicas, parangonable al de los Estados federales más consolidados, donde suele haber un reparto del gasto público cercano a la mitad, en términos medios, entre el nivel estatal y los subestatales. En España se está alcanzando ya este nivel, pero la diferencia está en la distribución del gasto público entre los dos niveles subestatales —el regional y el local-, ya que en los países más avanzados desde el punto de vista de la descentralización suele haber una participación del nivel local no inferior al 20\%, correspondiendo a las instancias regionales entre un 25 y un 30\%, mientras en España el nivel local a duras penas supera el $13 \%$.

En definitiva, el proceso descentralizador de la democracia española ha beneficiado de manera muy evidente al nivel de las Comunidades Autónomas, pero muy escasamente al local. Y evidentemente, esta situación exige un ensanchamiento del ámbito propio de las responsabilidades sustantivas de los Gobiernos locales o, si se prefiere decirlo así, una ampliación del campo propio de las políticas públicas locales.

Pero, además, hace falta adecuar a las nuevas circunstancias la distribución interna de funciones de los órganos locales y mejorar la gobernabilidad, en general, de nuestras Corporaciones locales, para que puedan ejercitar de manera eficaz y eficiente sus responsabilidades de Gobierno, lo que en la actualidad exige, esencialmente, un reforzamiento de las funciones ejecutivas de sus Presidentes y un fortalecimiento paralelo de las funciones de control de los órganos representativos plenarios, perfeccionando los mecanismos de relación y equilibrio institucional en- 
tre tales órganos que tengan incidencia en la capacidad de dirección de las Administraciones locales. Se trataría de buscar la máxima agilidad, eficacia y capacidad de gestión en los órganos ejecutivos, compensando ese "plus. de capacidad ejecutiva con una mayor posibilidad de control por parte de los órganos plenarios y una mayor transparencia en la gestión, actuando de forma que el sistema institucional interno de cada Entidad local se mueva dentro de un equilibrado modelo de checks and balances.

Pero tampoco basta con ello para el fortalecimiento de la autonomía local. Esta resulta ineludiblemente capitidisminuida si carece de las vías jurídicas precisas para reaccionar frente a los posibles vulneraciones o atentados que pueda experimentar como consecuencia de los actos o de la normativa emanada de otras instancias territoriales de poder. También en este sentido la posición de las Entidades locales ofrece en España una importante laguna que colmar, debido a la imposibilidad, en los términos actuales de la Ley Orgánica del Tribunal Constitucional, de acceder directamente ante dicho Tribunal, lo que impone la exigencia de explorar al máximo las posibilidades que la Constitución ofrece para hacer viable una vía de defensa de tal naturaleza, que permita reaccionar de una manera efectiva frente a la lesión del ámbito de autonomía de las Entidades locales.

Pues bien, es justamente a este conjunto de importantes necesidades, junto al establecimiento de otras mejoras de carácter técnico, al que responde ese proceso que denominamos "Pacto Locab, a cuyo proceso de gestación y desarrollo me referiré sucintamente a continuación.

Fue precisamente la constatación de estas circunstancias lo que condujo a la Federación Española de Municipios y Provincias (FEMP) ${ }^{9}$ a celebrar los dias 5 y 6 de noviembre de 1993 una Asamblea General Extraordinaria en la ciudad de A Coruña, en la que, tras constatar la profundidad del proceso descentralizador español, se declara que el mismo ha favorecido casi exclusivamente a las Comunidades Autónomas, mientras que la Administración local se encontraba, en su opinión, agredida por la legislación sectorial de las Comunidades Autónomas, representada desequilibradamente en el Comité de las Regiones de la Unión Europea (de los 21 miembros correspondientes a España, había 17 representantes autonómicos frente a 4 locales), sin posibilidad de acceso directo ante el Tribunal Constitucional para defender su autonomía, y con una participación en el gasto público total muy parecida en términos relativos a la existente en 1978.

Fue precisamente en el marco de esta Asamblea donde se elaboró la expresión "Pacto Locab, solicitándose esencialmente por la FEMP dos grandes líneas de actuación:

a) En primer lugar, el desarrollo del principio de subsidiariedad, o si se prefiere de aproximidadn: la Administra- ción local es la más cercana a los ciudadanos y, en consecuencia, debe jugar el papel de verdadera Administración Común, debiendo producirse, en su opinión, un importante traspaso de competencias desde las Comunidades Autónomas hacia las Entidades locales, bien con el carácter de propias, bien mediante la técnica de la delegación. En este sentido, las conclusiones de la Asamblea de la FEMP incorporan un amplio Anexo de las materias en las que se considera que debería ampliarse el marco competencial de las Entidades locales, que abarcan los campos de Deportes, Educación, Empleo, Juventud, Mujer, Servicios Sociales y Urbanismo.

b) En segundo lugar, e íntimamente relacionado con lo anterior, debería efectuarse una revisión en profundidad de la Ley de Haciendas Locales, de manera que, especialmente, se establezcan instrumentos fiscales más flexibles y se creen o se generalicen, al amparo de lo dispuesto en el artículo 142 de la Constitución, verdaderos fondos autonómicos de financiación de las Corporaciones locales de carácter no finalista.

Comienza así la andadura del proceso del "Pacto Local, en el que el siguiente paso fue el pronunciamiento por el anterior Presidente del Gobierno, Felipe González, del compromiso de llevar a cabo el Pacto Local, asumido en el marco del debate sobre el Estado de la nación del año 1995, seguido de la formalización de un documento en tal sentido, firmado por el Ministro para las Administraciones Públicas y el Presidente de la FEMP, documento que se trasladó a los Partidos Políticos, sin que se llegase a recibir la respuesta de todos ellos antes de la celebración de las Elecciones Generales de marzo de marzo de 1996, en las que el compromiso de desarrollo del "Pacto Locab. apareció en los programas de las principales fuerzas políticas.

En esta etapa se celebró la Asamblea General de la FEMP celebrada en Madrid en noviembre de 1995, en la que se sustancialmente se reiteraron y profundizaron los planteamientos de la celebrada en A Coruña. Al mismo tiempo, durante toda esta etapa en el seno del Ministerio para las Administraciones Públicas se realizaron estudios sobre las distintas materias en las que se podía ampliar el ámbito competencial de las Comunidades Autónomas.

Pero decisivo sería para la suerte futura del «Pacto Locab el respaldo definitivo que recibió por parte del nuevo Gobierno. En efecto, ya en su misma sesión de investidura como Presidente del Gobierno, José María Aznar asumió de forma inequívoca el compromiso de abordar y realizar el ‘Pacto Locab, firmándose el 21 de mayo de 1996 un Acuerdo entre el Ministro de Administraciones Públicas y la Presidenta de la FEMP, sobre la conveniencia de iniciar el proceso de materialización del Pacto Local, Acuerdo que recibió el respaldo del Presidente del Go- 
bierno en su reunión con las Comisión Ejecutiva de la FEMP celebrada el día 10 de junio de 1996.

A partir de ese momento se aprobó por la Comisión Ejecutiva de la FEMP el 24 de septiembre de 1996 un importante documento técnico y político, denominado -Bases para el Pacto Locab, en el que, esencialmente, se recogen reivindicaciones competenciales en una serie de ámbitos materiales (Circulación y Transportes, Consumo, Deportes, Educación, Empleo, Juventud, Medio Ambiente, Mujer, Protección Ciudadana, Sanidad, Servicios Sociales, Turismo y Urbanismo), y se solicitaba el acceso directo de las Entidades Locales al Tribunal Constitucional en defensa de su autonomía.

Este documento sirvió de base para la posterior negociación de la FEMP con el Ministerio de Administraciones Públicas, fruto del cual fue un decisivo documento denominado Bases para la negociación del Acuerdo para el Desarrollo del Gobierno Local, que fue propuesto por el Ministro de Administraciones Públicas al Consejo de Ministros en su reunión de fecha 30 de mayo de 1997, obteniendo el apoyo del Gobierno al mismo. Dicho documento iba acompañado de otro sobre los ámbitos materiales en los que existen reivindicaciones de las Entidades locales, a efectos meramente informativos y de impulso de posibles pactos locales autonómicos, pues el Gobierno de la Nación ha de ser plenamente respetuoso con el reparto constitucional de competencias.

La siguiente cuestión que debe plantearse es la del contenido, a grandes rasgos, del "Pacto Locab, tal y como es concebido en dicho documento. Muy sucintamente, pueden definirse tres ámbitos diferenciados en el marco del «Pacto Locah, que son los siguientes:

- En primer lugar, estaría compuesto por un acuerdo sobre una serie de materias sobre las que puede intervenir el Estado en virtud de diversos títulos competenciales, reforzando las responsabilidades de las Entidades locales en una serie de ámbitos funcionales, tales como el tráfico y la circulación o la seguridad ciudadana, por ejemplo. En estas materias el proceso supone la realización de una propuesta de negociación desde el Gobiemo del Estado a la FEMP y a los partidos políticos, concretándose los acuerdos adoptados en los correspondientes proyectos legislativos reformando la normativa sectorial correspondiente.

- En segundo lugar, se prevé un acuerdo sobre cuestiones cuya regulación corresponde al Estado, pero que no se refieren ya a ámbitos sectoriales de actuación, sino al propio papel y a la posición institucional de los Gobiernos locales, en su condición de elementos básicos de la organización territorial del Estado. Se trataría, con estas medidas, de fortalecer su gobernabilidad y las posibilidades de defensa de la autonomía local, incidiendo en leyes de la importancia de la Ley Reguladora de las Bases del Régimen Local, la Ley Orgánica del Régimen Electoral General y la Ley Orgánica del Tribunal Constitucional.

En este segundo bloque, al incidir también en materias de competencia estatal, la negociación se desarrollaría de acuerdo con el mismo esquema señalado en el grupo anterior, reflejándose en los oportunos cambios legislativos.

- Existe en el marco del •Pacto Locab un tercer e importante ámbito de negociación, constituido por los acuerdos sobre aquellas funciones y materias cuya competencia corresponde a las Comunidades Autónomas. Obviamente, el Estado es extraordinariamente respetuoso con el reparto constitucional de competencias, y se basaría en este terreno en el acuerdo y el compromiso exclusivo de los partidos políticos para trasladar a las instituciones autonómicas donde ostenten representación parlamentaria o ejerzan responsabilidades de gobierno la iniciativa de un proceso de atribución de competencias a las Entidades locales en sus respectivos ámbitos territoriales.

- Y todavía existe un cuarto ámbito de negociación, de naturaleza no estrictamente jurídica, sino esencialmente política, ya firmado en Madrid por la mayoría de las fuerzas políticas el día 7 de julio de 1998, consistente en la propuesta de un acuerdo sobre ética política, dirigido esencialmente a limitar en lo posible en el ámbito local la práctica del transfuguismo y sus perniciosos efectos sobre la gobernabilidad y la estabilidad de las Administraciones locales.

- Finalmente, no puede olvidarse la existencia de un quinto ámbito de actuación, no tratado en el documento últimamente citado, pero que constituye el objeto de un grupo específico de trabajo, cual es el de las $\mathrm{Ha}$ ciendas locales, en el que se tratan dos materias específicas: la fijación de la aportación estatal a las Haciendas locales para el quinquenio 1999-2003, y la reforma de la Ley de Haciendas Locales.

Antes de continuar, me parece importante destacar aquí tres características que presiden este proceso que denominamos "Pacto Local, y que se deducen de lo hasta ahora expuesto:

- En primer lugar, en su desarrollo se atribuye un papel decisivo a la negociación y al intento de compromiso con las Fuerzas Políticas.

- En segundo lugar, debe destacarse que se considera al movimiento asociativo local, a través de la FEMP, un interlocutor esencial en el proceso. 
- Y en tercer lugar, la necesidad de respetar íntegra y escrupulosamente el reparto constitucional de competencias entre el Estado y las Comunidades Autónomas.

Como resultado final de este proceso; el Gobierno elaboró una serie de Anteproyectos de reformas normativas del régimen lōcal español, negociado con la FEMP y con la mayoría de las fuerzas políticas parlamentarias, recogidos en un documento denominado "Medidas para el Desarrollo del Gobierno Local. Dichos Anteproyectos fueron posteriormente sometidos al Dictamen del Consejo de Estado y aprobados como Proyectos de Ley por el Consejo de Ministros en su reunión del día 17 de julio de 1998, remitiéndose al Congreso de los Diputados para su tramitación parlamentaria.

\section{Las principales reformas incluidas en las "medidas para el desarrollo del gobierno local" y su conexión con los principios de la Carta Europea de la Autonomía Local}

No es nuestra intención exponer aquí in extenso las reformas proyectadas en el régimen local español, sino destacar las medidas más relevantes en el contexto de los grandes principios de la Carta Europea de la Autonomía Local.

De entrada, debe señalarse que, por primera vez en la historia jurídica española, la Carta aparece profusamente citada e invocada en las Memorias justificativas y en las Exposiciones de Motivos de los Proyectos de Ley aprobados, para justificar buena parte de las medidas adoptadas ${ }^{10}$. Se trata de una clara incardinación de la reforma española en un conjunto de reformas del régimen local que se están produciendo en diversos países europeos, inspiradas en los grandes principios de la Carta (en los países de Europa central y oriental, pero también en Italia, en Suecia, en Noruega, etc.).

De esas reformas, merece la pena destacar especialmente las siguientes: a) Modificación del régimen de distribución de atribuciones entre el Presidente de la Corporación local y el Pleno (máximo órgano colegiado representativo) contenido en la Ley 7/1985, Reguladora de las Bases del Régimen local. La Ley citada supuso en su día un evidente paso adelante en la modemización del régimen local español, pero su modelo de reparto de atribuciones entre los diversos órganos reflejaba aún en cierta medida, y por inercia, el modelo preconstitucional, en el que el máximo órgano colegiado, junto a las funciones típicas de un órgano de tal naturaleza (presupuestos, aprobación de los tributos locales, funciones reglamentarias, planificación territorial, control de los demás órganos,..), asumía numerosas funciones típicamente ejecutivas y de gestión ${ }^{12}$.

El paso de los años ha ido poniendo de manifiesto y acentuando el carácter afuncional de dicho modelo para una gestión rápida y eficaz, y por eso la reforma prevé una redistribución de funciones con base en los siguientes criterios:

- Córresponde al Pleno, esencialmente, el ejercicio de las funciones de aprobación de los presupuestos, la potestad normativa (aprobación de reglamentos y ordenanzas locales), la potestad tributaria derivada (imposición y ordenación de tributos locảles), la de planificación territorial (aprobación de los planes e instrumentos de ordenación urbanística) y el control de los demás órganos de la Corporación. En materia de gestión, sus competencias se reducen a aquellas materias que, por sus efectos a largo plazo, condicionen o hipotequen a futuros gobiernos locales (grandes préstamos, contratos de larga duración o de importe muy elevado, adquisición o venta de bienes de gran valor...). También se facilita el funcionamiento del Pleno, al reducirse el número de asuntos que requieren mayorías especiales para su aprobación.

- Se amplian las atribuciones del Presidente de la Corporación, que pasa a ser el titular de todas las funciones de gestión, con las excepciones indicadas. Así, se ven ampliamente reforzadas sus funciones en materia de gestión de personal, de administración del patrimonio, de contratación, de gestión urbanística y de defensa jurídica de la Corporación, entre otras materias.

De esta forma adquiere plena efectividad la existencia de órganos ejecutivos diferenciados de los órganos plenarios representativos, que facilitan la agilidad y capacidad de gestión exigida por la sociedad contemporánea, siendo sin embargo plenamente responsables ante los segundos. 
b) Fortalecimiento de las funciones de control del Pleno sobre el Presidente y los demás órganos, previstas en la Ley 7/1985. Así se profundiza la responsabilidad de los órganos ejecutivos frente al representativo, en la linea señalada en el artículo 3.2 de la Carta, y se reequilibra adecuadamente el fortalecimiento de la capacidad de gestión de estos últimos a costa del Pleno. Tales medidas son, esencialmente, las siguientes:

- Se incrementa la frecuencia mínima de las sesiones ordinarias del órgano plenario, que son en las que esencialmente se realiza la función de control, pasando a ser mensuales en las Diputaciones, Cabildos y en los Ayuntamientos de municipios de más de 20.000 habitantes, y bimensual en los demás Ayuntamientos (la frecuencia mínima actual es trimestral en todas las Corporaciones locales).

- Se establece que en los plenos ordinarios la parte destinada al control tendrá sustantividad propia y diferenciada de la parte resolutiva, debiéndose garantizar de forma efectiva en su funcionamiento la participación de todos los grupos políticos en la formulación de ruegos, preguntas y mociones.

- Se prevé que los plenos extraordinarios convocados a petición de la cuarta parte, al menos, de los miembros electivos de la Corporación, no se podrá incorporar el correspondiente asunto a un pleno ordinario o a otro extraordinario sin la autorización expresa de los solicitantes de la convocatoria, convocatoria que además se producirá automáticamente si el Presidente no convoca al Pleno en un plazo de dos meses. No obstante, para evitar abusos en el ejercicio de este derecho, se prevé que se limitará a uno el número máximo de plenos extraordinarios anuales que pueda solicitar por esta vía cada miembro electivo.

- Se prevé que las Comisiones Informativas, que son órganos con funciones de estudio, informe o consulta de los asuntos que han de someterse a la decisión del Pleno, en las que están representados proporcionalmente todos los grupos políticos del Pleno (de hecho, son pequeños Plenos a escala) asuman la función del seguimiento de la gestión del Presidente y de los demás órganos de la Corporación, sin periuicio de las facultades de control que corresponden al Pleno, cuya labor en este terreno quedará notablemente facilitada por la tarea previa en las Comisiones Informativas. Además, estas Comisiones, cuya existencia hasta ahora era voluntaria, pasa a ser obligatoria en los Municipios de más de 5.000 habitantes y en las Diputaciones provinciales.

c) Mejora de los mecanismos de responsabilidad política del Presidente ante ei Pieno, previstos en ia Ley Orgánica 5/1985, del Régimen Electoral General. Esto se realiza mediante dos medidas - la reforma de la moción de censura y la introducción de la cuestión de confianza en el régimen local-, con las que también se da satisfacción al principio del artículo 3.2 de la Carta de que los órganos ejecutivos de las Entidades locales responden políticamente ante los órganos plenarios.

- En primer lugar, se realiza una profunda reforma técnica del procedimiento de las mociones de censura, que es un mecanismo por el que la mayoría del Pleno puede sustituir al Presidente proponiendo y apoyando a un candidato alternativo, también miembro del Pleno (moción de censura constructiva). La reforma busca introducir transparencia y automatismo en su tramitación y votación, intentando evitar en lo posible determinadas situaciones patológicas y de bloqueo que, aunque concretas y no generalizables, estaban proyectando de forma injusta una imagen negativa sobre la Administración local y su gobernabilidad, debido a su evidente carácter noticioso. Las patologías más comúnmente detectadas en este campo son la negativa del Presidente a convocar el Pleno en el que ha debatirse la cuestión (a lo que está obligado legalmente), bien alegando defectos formales del documento (legitimación de firmas, esencialmente), bien sin ninguna razón a efectos de ganar tiempo; y cuando al Pleno llega a celebrarse, la expulsión de algún concejal de la oposición con el argumento de que es incompatible por enemistad manifiesta, intentando aplicar incorrectamente a este terreno puramente político las normas concebidas para las abstenciones administrativas.

Para evitar este tipo de situaciones, se ha diseñado una moción de censura en la que el Pleno queda automáticamente convocado cuando se presenta, y para que se produzca tal automatismo se rodea el documento de una serie de garantías formales: las firmas han de estar legitimadas por el Secretario de la Corporación o por notario, y el Secretario de la Corporación debe extender en el documento una diligencia acreditativa del cumplimiento de los requisitos formales exigidos por la Ley (que quienes firman la moción sọn miembros de la Corporación, que constituyen mayoría absoluta, que proponen un candidato alternativo que es miembro de la Corporación y, además, que no han 
suscrito anteriormente durante el mandato otra moción de censura). Además, se prevé que el Pleno esté presidido por una mesa de edad, integrada por el miembro de la Corporación de mayor edad y el de menor edad, asistidos por el Secretario de la Corporación, sin que puedan ser parte de la misma ni el Presidente ni el candidato a la Presidencia de la Corporación local.

- Asimismo, se introduce por primera vez en nuestro Derecho local la institución de la cuestión de confianza, que pretende facilitar el desbloqueo de determinadas situaciones de parálisis o de rigidez en la dirección del Gobiemo local, vinculando la confianza a la aprobación de acuerdos concretos de naturaleza inequivocamente estratégica, como son los Presupuestos, el Reglamento Orgánico, el Planeamiento Urbanístico General o las Ordenanzas Fiscales. De esta forma, si se aprueban tales acuerdos, se entiende concedida la confianza al Presidente de la Corporación, pero en caso contrario se entenderá denegada, con el efecto de que cesa automáticamente, debiendo precederse a elegir nuevo Presidente por el Pleno.

Es cierto que el Presidente de una Corporación local puede en la actualidad simplemente presentar su dimisión si considera que ya no tiene la mayoría necesaria para realizar su gestión. Pero la cuestión de confianza cumple con una función política específica: permite hacer patentes y públicos los apoyos perdidos y los cambios de posición política que están afectando a la gobernabilidad de la Entidad local, y obligan a todos los miembros del Pleno a definirse formalmente ante las situaciones de bloqueo.

d) Debe destacarse de manera muy señalada la introducción en la Ley Orgănica 2/1979, del Tribunal Constitucional, de un aconflicto para la defensa de la autonomía localn, mediante el cual las Corporaciones locales pueden acudir directamente ante dicho Tribunal cuando consideren que una ley autonómica o determinadas leyes estatales vulneran el ámbito competencial de su autonomía, siempre que representen un determinado porcentaje de las Entidades locales del ámbito de aplicación de la norma (al menos un sexto en el caso de los Municipios y la mitad en el de las provincias) y de la población de dicho ámbito (que representen al menos un sexto de la poblacion en el caso de los Municipios, y la mitad en el de las Provincias), salvo que se trate de leyes que les afecten singularmente, en cuyo caso están legitimados para acudir individualizadamente a dicho Tribunal.
Se trata de una medida que tiene extraordinarias consecuencias políticas, absolutamente novedosa en España, con la que se da satisfacción a la previsión de la posibilidad de uso por las Entidades locales de vías para la defensa de su autonomía, contenida en el artículo 11 de la Carta. Pero si todas las medidas anteriormente contempladas afectaban al equilibrio de poderes, a los checks and balances del subsistema político local (o, si se prefiere, de los distintos subsistemas políticos locales), ésta afecta a los equilibrios del sistema político e institucional en su conjunto, confiriendo a las Entidades locales un arma poderosa para poder reaccionar frente a la legislación del Estado o de las Comunidades Autónomas que afecten a su autonomía (efecto reactivo), algo hasta ahora imposible. La mera existencia de esta posibilidad obligará a una mayor reflexión a la hora de elaborar la legislación sectorial por parte de las otras instancias territoriales de poder (efecto preventivo), poniendo más celo en evitar una limitación o una de las competencias locales o una atribución restrictiva que no tenga en cuenta el principio de subsidiariedad, consagrado en el artículo 4.3 de la Carta.

Por otra parte, no puede olvidarse que la exigencia, ordinariamente, de un determinado número de Entidades locales para poder usar esta vía, fortalece el papel de las asociaciones de promoción y defensa de sus intereses comunes, consagradas en el artículo 10 de la Carta, especialmente de las de amplia implantación, tanto como interlocutores válidos de las otras instancias territoriales de poder en los procesos de elaboración normativa, como a la hora de reaccionar frente a los atentados contra la autonomía local.

\section{El camino por recorrer}

Creemos que con este conjunto de medidas, por lo que a las responsabilidades constitucionales del Estado se refiere, se colma en buena medida el espacio que el desarrollo de la autonomía local requiere en nuestro país para dar cumplimiento a la Carta Europea de la Autonomía Local. Pero aún quedan importantes etapas que realizar.

En primer lugar, el fortalecimiento de la autonomía y la suficiencia financiera, contempladas en el artículo 7 de la Carta, admite aún amplios desarrollos por el Estado y, sobre todo, por las Comunidades Autónomas. Por lo que al primero se refiere, estas expectativas se podrán confirmar a corto plazo, con la fijación de la participación de las Entidades locales en los tributos del Estado para el próximo quinquenio, así como con la reforma de la Ley de Haciendas Locales. Pero no puede dejar de recordarse que también las Comunidades Autónomas tienen una importancia destacada en la financiación de las Haciendas locales, puesto que, por imperativo del artículo $142 \mathrm{dc}$ la Constitu- 
ción, una parte de su financiación ha de proceder de su participación en los Tributos de las Comunidades Autónomas. Esto, combinado con la preferencia de la financiación no finalista en la Carta Europea de la Autonomía Local, debería conducir a la generalización en todas las Comunidades Autónomas de fondos no finalistas, o preferentemente no finalistas, para la financiación de sus Entidades locales, sin perjuicio de las subvenciones que puedan conceder para programas o actuaciones sectoriales concretas. Algo que aún no ocurre en todas las Comunidades Autónomas.

En segundo lugar, el principio de subsidiariedad exige una mayor atribución de competencias a las Entidades locales. Pero la mayor parte de estas competencias pertenecen hoy día a las Comunidades Autónomas, de acuerdo con sus respectivos Estatutos de Autonomía. El Estado no puede aquí imponer soluciones a las Comunidades Autónomas, pues ello sería tanto como invadir su ámbito de competencias propias. Tan sólo puede jugar un papel de estímulo, y ya lo ha hecho al elaborar un documento en el que, de forma coordinada con la FEMP, se exponen las grandes materias en las que existen demandas del poder local español en las que la decisión corresponde a las Comunidades Autónomas. En el mismo se abordan numerosas medidas de fortalecimiento competencial en materias como consumo, urbanismo, sanidad, patrimonio histórico-artístico, deportes, empleo, mujer, juventud, turismo, vivienda, etc. Es todo lo que se podía hacer en este terreno, y se ha hecho.

Por lo tanto, será cada Comunidad Autónoma la que deberá negociar con sus Entidades locales para proceder a ese camino de fortalecimiento competencial que están demandando de acuerdo con las singularidades de cada parte del territorio, y mediante un proceso normalmente consensuado, teniendo por interlocutor a las asociaciones de entidades locales más representativas en su territorio, que asumen en esta materia un protagonismo esencial. Y ya hay ejemplos de la iniciación de este proceso en varias Comunidades Autónomas (La Rioja, Galicia, Murcia, Canarias, etc.). Se trata, además, de un proceso absolutamente necesario, porque al estar la mayor parte de las materias en las que debe reforzarse el campo de competencias están en manos de las Comunidades Autónomas, sin su iniciativa y generosidad se pueden ver frustradas parte de las expectativas del poder local español para el logro de una mayor descentralización, que responde, por otra parte, a un proceso general no sólo en España, sino a nivel europeo e incluso mundial, estimulado con mayor o menor intensidad por todas las instancias internacionales de prestigio (Unión Europea, Conséjo de Europa, Naciones Unidas, ...).

Precisamente quisiera finalizar este trabajo reiterando la incardinación del aPacto Local. en los procesos de fortalecimiento del poder local en el nivel europeo, que encuentran en la Carta Europea de la Autonomía Local el marco normativo e ideológico idóneo para su fundamentación, al responder a los criterios más consolidados de la tradición democrática europea, estableciendo como ejes fundamentales los principios de democracia y de subsidiariedad. Esas ideas y ese Convenio Internacional están presidiendo los esfuerzos por fortalecer la autonomía local en España, de forma que incluso, por primera vez en este país, la Carta Europea de la Autonomía local se invoca y se destaca expresamente en los preámbulos y las exposiciones dé motivos de los documentos normativos que integran las «Medidas para el Desarrollo del Gobierno Local.
- Texto de Ponència presentada en el III Congreso Internacional del CLAD sobre la Reforma del Estado y de la Administración Pública, celebrado en Madrid los días 14 a 17 de octubre de 1998.

- Subdirector General Adjunto de Cooperación y Régimen Jurídico Local. Profesor Asociado del Departamento de Ciencia Políica y de la Administración de la Universidad Autónoma de Madrid.

1 Daniel Tarschys, en el Prefacio a la obra de José Manuel Rodriguez Álvarez: la Carta Europea de la Autonomia Local. Su significación en el ordenamiento juridico español; Barcelona, Bayer Hermanos, 1996. En esta obra puede encontrase una amplia exposición del contenido de la Carta.

' España la firmó el mismo día de su apertura a la firma, y la ratificó el 20 de enero de 1988, publicándose íntegramente en el Boletín Oficial del Estado de 24 de febrero de 1989 .

'Para un detallado estudio del proceso de elaboración de la Carta Europea de la Autonomía Iocal, véase M.A. CloteT I Miro: La cooperación internacional de los Municipios en el seno del Consejo de Europa, Madrid, Civitas, 1992, pp. 220 y ss.; José Manuel Rodríguez Álvarez: La Carta Europea..., op. cit., pp. 67 y ss.; y A. VIZÁN FE. RRO: -La Carta Europea de Autonomía Local, Madrid, Revista Autonomía Local, n. ${ }^{*} 3$, (ag.- sep. 1983), in totum.
' Sobre esta materia, véase la excelente obra de Jordi BoRja y Manuel Castells: Local y global. la gestión de las ciudades en la era de la información, Madrid, Santillana/Taurus, 1997, in totum.

IULA: Intermational Union of Local Authorities o Unión Intemacional de Poderes Locales, que goza de estatuto consultivo ante el Consejo Económico y Social de las Naciones Unidas, la UNESCO y la OMS, y desde 1954 ante el Consejo de Europa. Ya en su Congreso de Río de Janeiro de 1985 aprobó una -Declaración Universal de la Autonomía Local, inspirándose en la Carta Europea.

${ }^{6}$ En definitiva, el principio de subsidiariedad se orienta a la mejora de los resultados o performances en un contexto democrático.

" La Parte Segunda de la Carta (arts. 12 a 14) se refiere a los compromisos asumidos por las partes signatarias del. Convenio en orden a su aplicación y la comunicación de informaciones al respecto a la Secretaría General del Consejo de Europa, mientras que la Parte Tercera (arts. 15 a 17) contiene las clásicas estipulaciones de los Convenios intemacionales sobre forma, ratificación, entrada en vigor, modificación de los territorios a los que se aplica, denuncia y notificaciones de estos actos a la Secretaría General de la Organización.

- Debe tenerse en cuenta que, como es tradicional, la Carta aplica la técnica del Sofi Law (derecho blando), de manera que, para facilitar la ratificación de los Estados 
miembros del Consejo de Europa, éstos no están obligados a ratificar de entrada todo su contenido, sino que, de acuerdo con su articulo 12, pueden limitarse a ratificar 20 de los 31 apartados que integran su Parte Primera. Ahora bien, de esos 20, 10 al menos deben serlo de un enúcleo obligatorio (noyeau obligatoire) de 14 apartados, que son los siguientes: art. 2; art. 3, apartados 1 y 2; art. 4, apartados 1,2 y 4; art. 5; art. 7, apartado 1 ; art. 8, apartado 2; art. 9, apartados 1,2 y 3 ; art. 10. apartado $1 ; y$ art. 11.

${ }^{8}$ Una síntesis de las políicas públicas locales en la España democrática puede encontrase en Joan SUBiRaTS: -Gobierno local y políticas públicas. Apuntes en la España de los 90, artículo publicado en la Revista Valenciana d'Estudis Autonòmics, n.. 15 (febrero-mayo de 1996), pp. 19 y ss.); y en José Manuel Rodriguez ÁlvareZ: ·Importancia de la formación y de la capacitación en los procesos de desarrollo municipal., trabajo publicado en la obra Jomadas Internacionales de desarrollo local, Escuela Superior de Administración Pública de Colombia, Santa Fe de Bogotá, 1997, pp. 21 a 40.

Por lo que se refiere a las políticas locales y urbanas en el ámbito de la Unión Europea, véase Manuel ARENILIA SAEZ: .Las Políticas Locales Europeas o el Desarrollo Integrado como método, y José Manuel Rodríguez Álvarez: la Política Uibana de la
Unión Europear, artículos ambos publicados en la Revista de Estudios Locales CUNAL, Madrid, n. extraordinario de julio de 1998.

$?$ La FEMP es, con mucha diferencia, la principal asociación de Entidades locales española. En diciembre de 1997 agrupaba a 5.359 de los 8.099 Municipios españoles, con una población total de 36.454 .292 habitantes, lo que supone el $90,12 \%$ de la población total española; a 37 Diputaciones provinciales (de un total de 38); a los tres Consejos insulares de Baleares y a los siete Cabildos insulares canarios. Es, además, la Sección Española del Consejo de Municipios y Regiones de Europa (CMRE) y sede de la Organización Iberoamericana de Cooperación Intermunicipal.

I" Así, por ejemplo, en las Exposiciones de Motivos de los Proyectos de Reforma de la Ley 7/1985, Reguladora de las Bases del Régimen Local, y de la Ley Orgánica 2/1979, del Tribunal Constiucional, y en las Memorias Justificativas de dichos Proyectos y del de Reforma de la Ley Orgánica 5/1985, del Régimen Electoral General.

" Este tema aparece excelentemente desarrollado por Miguel SáNCHEZ MORON en -El sistema político local: fórmulas de gobiemo y participación ciudadana, en Informe sobre el Gobiemo Local, Madrid, MAP y Fundació Carles Pi i Sunyer d'Estudis Autonòmics i Locals, 1992, pp. 289 a 321. 